\title{
Root causes and organic budgeting: funding health from conception to the grave
}
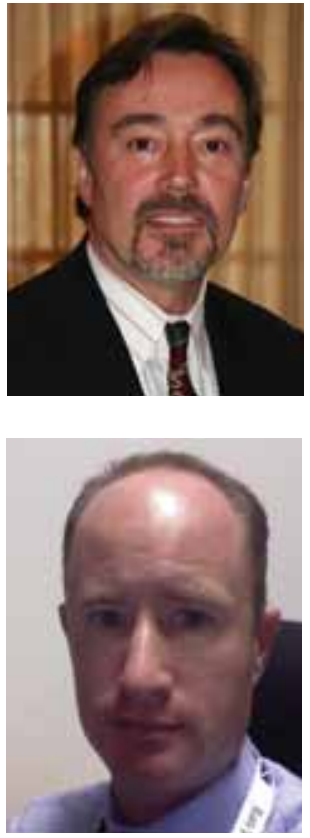

\section{RdbertF Anda \& David W Brown}

${ }^{\dagger}$ Author for correspondence Centers for D isease C ontrol and Prevention, 4770 Buford H wy NE (M S K67) Atlanta, GA 30341, USA E-mail: rfal@cdc.gov
'Thus, ACEs become biology, leading to social, emotional and cognitive impairments that inc rea se the risk of unhealthy (but probably ada ptive) behaviors, risk of violence or revic timization, poor psychosocial functioning, disea se and disa bility.'

Place: 'D eveloped' country. Time: Present day. Event: A sperm penetrates an egg. M onths later, a child born at term, without identifiable genetic defects, normal birth weight, APG AR 10, and all organ systems exquisitely formed. Fantastic!

Supposition 1: For a child like this, social determinants of health [101] are the major forces that affect your public-health goal of 'wellness in every stage of life' [102].

Supposition 2: You have sole power over the economic resources of your nation. Challenge: As holder of this economic power, your challenge is to choose the major predictor of this newborn child's future social and cognitive development, health and wellbeing, adolescent and adult behavior, physical and mental health, adult functioning, risk for a variety of diseases, and cause of death. To determine where to place the money that will shape public-health policy and services that meets all of these needs, you must place a bet on the 'root' origins of health and well being for children.

Your choices: We live in a world of categorical thinking and categorical funding, so you only get one choice for your bet. Would you choose access to healthcare [1]? School achievement [103]? Racial disparities in health [2]? Socioeconomic status [3]? Poverty [104]?

N ow, consider the life stages in reverse order, since a ranking of health expenditures - from highest to lowest - would be ranked similarly.

Start with the last stage of life: dying. In 1993, M CG innis and Foege quantified the contribution of adverse health behaviors (e.g., smoking, alcohol use and physical inactivity) to the leading causes of death, which they termed the 'actual' causes of death, in the
U SA [4], a huge step forward for thinking about using your nation's health resources! If you also were aware of a common set of biologically plausible exposures that increase the risk of these nonrandom adverse health behaviors, you might term these the root causes of death.

$N$ ext stage: adult health. Consider some of the major causes of a lack of wellbeing, and morbidity, in adults. The list would include heart, lung and liver disease, obesity, substance abuse, depression, anxiety, sexually transmitted diseases and intimate-partner violence. And do not forget important problems with respect to functioning as an adult, such as inability to maintain lasting relationships, nurture children, manage finances or perform in the workforce.

N ow, move backward again in time to the stage we call adolescence. The list of major issues would include early intercourse, teen smoking, alcohol or drug use, teen pregnancy and paternity, suicide attempts, violence and poor school performance.

\footnotetext{
'...we believe the priority should be for children and public-health policy: reduce the cumulative exposure of child ren to the activa ted stress response during critical periods of neurodevelopment.
}

Consider the in utero life stage. $C$ an the same root causes play a role in spontaneous abortion or fetal death? Evidence is also emerging to suggest that these root causes exposures may alter genomic expression, helping you tie this all together from generation to generation [5].

You enlist a group of experts on health and social services to help you develop a list of top priorities across the lifespan that that will inform your decision. The following problems would probably appear on your list:

- Prevalent diseases: ischemic heart disease, stroke, cancer, chronic lung disease, skeletal fractures, sexually transmitted diseases, diabetes, liver disease, suicide attempts;

- Risk factors for common diseases/poor health: smoking, alcohol abuse, promiscuity, obesity, illicit drug use, injected drug use, multiple 
somatic symptoms, poor self-rated health, self-reported high risk of AID S;

- Poor mental health: depressive disorders, anxiety, hallucinations, panic reactions, sleep disturbances, memory disturbances, poor anger control, risk of perpetrating or being a victim of domestic violence;

- Sexual and reproductive health: early age at first intercourse, sexual dissatisfaction, teen pregnancy, unintended pregnancy, teen paternity, spontaneous abortion or fetal death;

- Poor general health and social problems: high perceived stress, inability to maintain a marriage relationship, marriage to an alcoholic;

- O bviously expensive items: difficulty with job performance, prescriptions for psychotropic drugs, unexplained medical symptoms.

'The ACE Score has a strong dose-response relationship to every problem on your list of health priorities from your consultants.'

\section{The Roots}

W hat preventable exposure do all of these priorities have in common? O ur choice (sorry, it was not on your list) comes from a study of a cohort of more than 17,000 adults surveyed during 1995-1997 as part of the Adverse Childhood Experiences (ACE) study [6]; all were enrolled in a health-maintenance organization in San Diego (CA, USA), so they all had access to healthcare. Moreover, they are a well-educated group of Americans: $40 \%$ were college graduates, $36 \%$ had some college education and $17 \%$ were highschool graduates. Only 7\% had not graduated from high school. These are people who have, on average, done 'better' than the general population of the country in which they reside. So, from a socioeconomic standpoint, things are looking pretty good, at least on the surface.

The individual 'ACES' and their prevalence in this study population were common. Their prevalence was as follows [7]:

- Abuse (emotional: 10.2\%; physical: 26.4\%; sexual: $21.0 \%$ )

- N eglect (emotional: 14.8\%; physical: 9.9\%)

- Witnessing domestic violence: $13.0 \%$

- Household members who abuse alcohol or drugs (28.2\%) or are mentally ill (20.3\%)

- Parental separation or divorce: $24.1 \%$

- Imprisonment of a household member: $6.0 \%$
In the study cohort, ACEs are highly interrelated such that a child who experiences one usually experiences several others [7]. The number of ACEs was counted to create an 'ACE Score' that was designed to capture the cumulative exposure to this variety of highly interrelated stressful exposures. The ACE Scores in this well-educated population of 17,000 people were: $0: 33 \% ; 1: 26 \% ; 2: 15 \% ; 3: 10 \%$; 4 or more: $20 \%$ [7]. It seems logical to assume that ACE Scores would probably look worse in most other populations.

The ACE Score has a strong dose-response relationship to every problem on your list of health priorities from your consultants $[105,106]$. The biologically plausible mechanism potentially linking ACEs to all of these problems is grounded in findings from studies of the effects of stress on neurodevelopment. Breakthroughs in neurobiology show that excessive stress disrupts neurodevelopment and can have profound lasting effects on brain structure and function [8]; these biologic pathways likely explain the strength of the findings from the ACE Study [9]. Thus, ACEs become biology, leading to social, emotional and cognitive impairments that increase the risk of unhealthy (but probably adaptive) behaviors, risk of violence or revictimization, poor psychosocial functioning, disease and disability. This is where we believe the priority should be for children and public-health policy: reduce the cumulative exposure of children to the activated stress response during critical periods of neurodevelopment $[8,9]$.

$\mathrm{O}$ thers, including a N obel laureate economist, have asserted that [10]:

\section{"... the most efficient strategy for strengthening the} future workforce both economically and neurobiologically, and improving its quality of life isto invest in the envi ronments of disadvantaged children during the early childhood years"

If ACEs are considered root causes of healthrelated problems in your country, other social disadvantages such as racism, poverty, socioeconomic status and access to healthcare are the 'soil' in which these roots are embedded.

Plants die and decompose, and the roots become new soil. Each sustains the other.

O rganic budgeting anyone?

Additional information

The ACE Study questionnaires are included as an Appendix within Preventing Child M altreatment: 


\author{
A Guide to Taking Action and Generating Evi- \\ dence, available from the W H $O$ [107]. M ore infor- \\ mation regarding the ACE study is available \\ online $[105,108]$. \\ Disclaimer \\ The findings and conclusions in this report are those of the \\ author(s) and do not represent the views of the Centers for \\ Disease Control and Prevention.
}

Financial \& competing interests disclosure Theauthorshave no relevant affiliations or financial involve ment with any organization or entity with a financial interest in or financial conflict with the subject matter or materials discussed in the manuscript. This indudes employment, consultancies, honoraria, stock ownership or options, expert tetimony, grants or patents rece ved or pending, or royalties.

No writing assistance was utilized in the production of this manuscript.

\section{Bibliography}

1. Mackenbach JP: An analysis of the role of health care in reducing socioeconomic inequalities in health: the case of the N etherlands. Int. J. H ealth Serv. 33(3), 523-541 (2003).

2. Satcher $D$, Fryer $G E, M c C$ ann J, Troutman A, Woolf SH , Rust G: What if we were equal? A comparison of the black-white mortality gap in 1960 and 2000. Health Aff. (M illwood) 24(2), 459-464 (2005).

3. Isaacs S, Schroeder S: Class - the ignored determinant of the nation's health. N. Engl. J. M ed. 351(11), 1137-1142 (2004).

4. M CGinnis JM, Foege W H : Actual causes of death in the United States. JAM A 270(18), 2207-2212 (1993).

5. Champagne FA, Curley JP: H ow social experience influence the brain. Curr. 0 pin. N eurobiol. 15, 704-709 (2005).

6. Felitti VJ, Anda RF, N ordenberg D et al.: The relationship of adult health status to childhood abuse and household dysfunction. Am. J. Prev. M ed. 14, 245-258 (1998).

7. Dong M , Anda RF, Felitti VJ et al.: The interrelatedness of multiple forms of childhood abuse, neglect, and household dysfunction. Child Abuse N egl. 28(7), 771-84 (2004).

8. Teicher M H, Andersen SL, Polcari A, Anderson CM , N avalta CP: D evelopmental neurobiology of childhood stress and trauma. Psychiatr. Clin. N orth Am. 25(2), 397-426 (2002).

9. Anda RF, Felitti VJ, Walker J et al.: The enduring effects of abuse and related adverse experiences in childhood: a convergence of evidence from neurobiology and epidemiology. Eur. Arch. Psychiatry Clin. N eurosci. 256(3), 174-186 (2006).

10. Knudsen EI, H eckman JJ, C ameron J, Shonkoff JP: Building America's future workforce: economic, neurobiological and behavioral perspectives on investment in human skill development. Proc. N atl Acad. Sci. U SA 103(27), 10155-10162 (2006).

\section{Websites}

101. M etzler $M$ : Social determinants of health: what, how, why, and now. Prev. Chronic Dis. 4(4) (2007) www.cdc.gov/pcd/issues/2007/oct/ 07_0136.htm

102. Steinberg $\mathrm{K}$ : Wellness in every stage of life: a new paradigm for public health programs. Prev. Chronic D is. [serial online] (2007) www.cdc.gov/pcd/issues/2007/jan/ 06 0120.htm

103. Freudenberg N, Ruglis]: Reframing school dropout as a public health issue. Prev. Chronic D is. 4(4) (2007) www.cdc.gov/pcd/issues/2007/oct/ 07_0063.htm.

104. Braveman P: D o we have real poverty in the United States of America? Prev. Chronic Dis. 4(4), (2007) www.cdc.gov/pcd/issues/2007/oct/ 07_0124.htm

105. Anda R: The health and social impact of growing up with adverse childhood experiences: human and economic costs of the status quo. Adverse childhood experiences (Accessed 10/31/07) www.acestudy.org

106. CDC Adverse Childhood Experiences (released July 2005) http://webdev.nccd.cdc.gov/nccdphp/ace/ index.htm

107. WH O Violence and Injury Prevention and Disability www.who.int/violence_injury_prevention/ violence

108. CD C: Adverse Childhood Experiences Study www.cdc.gov/N CCD PH P/ACE 